\title{
Molecular and antigenic characterisation of ribosomal phosphoprotein P0 from Babesia bovis
}

\author{
Carlos AN Ramos ${ }^{1,2}$, Flábio R Araújoº ${ }^{+}$, Ingrid IF Souza², Renato HM Oliveira ${ }^{2}$, Carina Elisei ${ }^{2}$, \\ Cleber O Soares², Ana MS Sacco ${ }^{3}$, Grácia MS Rosinha' ${ }^{2}$, Leucio C Alves ${ }^{1}$ \\ 'Departamento de Medicina Veterinária, Universidade Federal Rural de Pernambuco, Recife, PE, Brasil \\ 2Embrapa Gado de Corte, BR262 km4 CP154, 79002970 Campo Grande, MS, Brasil Embrapa Pecuária Sul, Bagé, RS, Brasil
}

\begin{abstract}
Babesia bovis is a tick-borne pathogen that remains an important constraint for the development of cattle industries in tropical and subtropical regions of the world. Effective control can be achieved by vaccination with live attenuated phenotypes of the parasite. However, these phenotypes have a number of drawbacks, which justifies the search for new, more efficient immunogens based mainly on recombinant protein technology. In the present paper, ribosomal phosphoprotein $\mathrm{P} 0$ from a Brazilian isolate of $\mathrm{B}$. bovis was produced and evaluated with regard to conservation and antigenicity. The protein sequence displayed high conservation between different Brazilian isolates of $\mathrm{B}$. bovis and several Apicomplexa parasites such as Theileria, Neospora and Toxoplasma. IgG from cattle experimentally and naturally infected with $\mathrm{B}$. bovis as well as $\operatorname{Ig} G_{1}$ and $\operatorname{Ig} G_{2}$ from naturally infected cattle reacted with the recombinant protein. $\operatorname{Ig} G$ from cattle experimentally infected with Babesia bigemina cross-reacted with $B$. bovis recombinant $P 0$. These characteristics suggest that $P 0$ is a potential antigen for recombinant vaccine preparations against bovine babesiosis.
\end{abstract}

Key words: Babesia bovis - babesiosis - bovine - recombinant ribosomal phosphoprotein

Bovine babesiosis caused by Babesia bovis and Babesia bigemina continues to be an economically important disease with wide distribution in tropical and subtropical regions, where the common arthropod vector Rhipicephalus microplus (Murrel \& Barker 2003) occurs (Bock et al. 2004). B. bovis causes the most pathogenic disease among parasites of the genus, resulting from sequestration of infected erythrocytes in the microcapillary endothelia of vital organs and a hypotensive shock syndrome denominated cerebral babesiosis, which is often fatal to susceptible cattle (Wright \& Goodger 1988, Clark \& Jacobsen 1998). Cattle that survive initial infection, either naturally or following chemotherapy, remain persistently infected and resistant to clinical disease, thereby allowing the use of attenuated phenotypes as live vaccines. However, these vaccines have limitations, including the transmission of other blood-borne pathogens and failure due to vaccine breakdowns (de Vos \& Bock 2000), which justifies the search for new, more efficient immunogens.

Advances in molecular techniques have led to the discovery and evaluation of many subunit antigens of $B$. bovis in recent years, which have provided antigens of the parasite with immunogenic and antigenic potential (Gaffar et al. 2004, Brown et al. 2006, Brayton et al. 2007, Bono et al. 2008). P0 is a neutral protein found in

Financial support: EC (INCO 003691-MEDLABAB), CNPq, FUNDECT, FACEPE

+ Corresponding author: flabio@cnpgc.embrapa.br

Received 26 May 2009

Accepted 23 September 2009 all eukaryotic organisms (Rich \& Steitz 1987) and is a component of a family of ribosomal phosphoproteins, together with P1 and P2 (Rajeshwari et al. 2004). P0 (but not P1 and P2) is of vital importance to cells, as demonstrated in Saccharomyces cerevisiae (Santos \& Ballesta 1994). Although a ribosomal component, this protein has been located on the surface of many eukaryotic cells, including many protozoan parasites (Singh et al. 2002), which may at least partially explain the antigenicity and immunogenicity of $\mathrm{P} 0$ against Plasmodium yoellii, Leishmania major and Babesia microti (Chatterjee et al. 2000, Iborra et al. 2005, Terkawi et al. 2007b). Moreover, in vitro studies have demonstrated that anti-P0 antiserum can neutralise Toxoplasma gondii, Neospora caninum and B. bovis parasites by either inhibiting their growth or blocking cell invasion (Sehgal et al. 2003, Terkawi et al. 2007a, Zhang et al. 2007). Thus, we hypothesise that $\mathrm{P} 0$ is a potential candidate as an immunogen against bovine babesiosis.

The aims of the present paper were to analyse the genetic conservation of the $\mathrm{P} 0$ gene among Brazilian isolates of B. bovis and produce recombinant $\mathrm{P} 0(\mathrm{rPO})$ from a Brazilian isolate and evaluate its antigenicity with sera from cattle naturally or experimentally infected with $B$. bovis and sera from cattle experimentally infected with $B$. bigemina in an enzyme-linked immunosorbent assay (ELISA).

\section{MATERIAL AND METHODS}

Isolates - Five Brazilian isolates of $B$. bovis were used. The isolates were from the states of Bahia, São Paulo, Rio Grande do Sul (RS), Mato Grosso do Sul and Rondônia, representing all physiographic Regions of Brazil (Northeast, Southeast, South, Midwest and North, respectively). 
Gene sequencing and analysis - Whole ORFs of the $\mathrm{P} 0$ gene from the five Brazilian isolates of $B$. bovis were amplified by polymerase chain reaction (PCR) and cloned into $p G E M-T$ Easy (Promega, USA) for sequence analysis, following the manufacturer's instructions. Amplifications of the whole gene were performed in two steps using the primer sets $\mathrm{P} 0-1 \mathrm{~F}$ 5'-ATGGCTCGCATGAGCAAG-3' and P0-1R 5'-ACCCTGTCGTTAACCTTGATGA-3' and P0-2F 5'-ATGTCCACCTCATCAAGGTTAAC-3' and P0-2R 5'-TTAGTCAAAGAGGGAGAATCCC-3' to produce two amplicons. Amplification reactions were performed in a volume of $25 \mu \mathrm{L}$ containing $10 \mathrm{mM}$ Tris$\mathrm{HCl}$ (pH 8.3), $50 \mathrm{mM} \mathrm{KCl}, 1.5 \mathrm{mM} \mathrm{MgCl}_{2}, 0.2 \mathrm{mM}$ of each deoxynucleoside triphosphate, $12 \mathrm{pmol}$ of each primer, $100 \mathrm{ng}$ of genomic DNA and 1.25 U of Taq DNA polymerase (Cenbiot, Brazil). Amplifications were performed in a Mastercycler thermocycler (Eppendorf, Germany) as follows: $94^{\circ} \mathrm{C}$ for $1 \mathrm{~min}$ (denaturation); 30 cycles of $94^{\circ} \mathrm{C}$ for $1 \mathrm{~min}$ (denaturation), $53^{\circ} \mathrm{C}$ for $30 \mathrm{sec}$ (annealing) and $72^{\circ} \mathrm{C}$ for $40 \mathrm{sec}$ (extension) and a final cycle at $72^{\circ} \mathrm{C}$ for $4 \mathrm{~min}$ (extension). PCR products were analysed by electrophoresis on $1 \%$ agarose gels stained with SybrGold (Invitrogen, USA).

The DNA sequences of P0 from five Brazilian isolates of $B$. bovis were obtained using the BigDye Terminator kit (Applied Biosystems, USA). Sequences were assembled using the Sequencher v.4.1.4 software program (Gene Codes, USA) and submitted to BLASTn search (http://www.ncbi.nlm.nih.gov) to verify the sequence identity. Multiple sequence alignment was performed with the ClustalW algorithm (www.ebi.ac.uk/ Tools/clustalw2/index.html).

Phylogenetic analyses were conducted with deduced amino acid sequences of $\mathrm{P} 0$ from Brazilian isolates of B. bovis, other species of Babesia, other Apicomplexa and Bos taurus using the MEGA software program, version 4.0 (Tamura et al. 2007). A phylogenetic tree was generated using the neighbour-joining method (Saitou \& Nei 1987) and a bootstrap resampling technique of 1,000 replications was performed to statistically support the reliabilities of the nodes on the trees (Felsenstein 1985).

Cloning and expression - DNA from the southern Brazilian isolate of $B$. bovis was used to amplify the complete ORF of P0 by PCR using the primer set P0-1F and $\mathrm{P} 0-2 \mathrm{R}$. The amplification reaction was performed in a volume of $25 \mu \mathrm{L}$, as described above, with an initial denaturing step of $95^{\circ} \mathrm{C}$ for 3 min followed by 35 cycles of $95^{\circ} \mathrm{C}$ for $1 \mathrm{~min}, 58^{\circ} \mathrm{C}$ for $30 \mathrm{sec}$ and $72^{\circ} \mathrm{C}$ for $1 \mathrm{~min}$ and a final extension step at $72^{\circ} \mathrm{C}$ for $4 \mathrm{~min}$.

The amplicon was initially cloned into $p G E M-T$ Easy (Promega, USA) and subsequently sub-cloned into the $p R S E T-c$ (Invitrogen, USA) EcoRI site. Chemically competent Escherichia coli host strain BL-21 cells were transformed with recombinant plasmid ( $p R S E T-c / \mathrm{P} 0)$ and the transformation was spread on selective plates containing Luria Bertani (LB) medium supplemented with $100 \mu \mathrm{g} / \mathrm{mL}$ ampicillin and $34 \mu \mathrm{g} /$ $\mathrm{mL}$ chloramphenicol. The expression of the $\mathrm{P} 0$ gene was carried out in LB broth with the addition of $1 \mathrm{mM}$ isopropyl- $\beta$-D-galactopyranoside.
The purification of rP0 was carried out with agarose$\mathrm{Ni}+$ resin (ProBond, Invitrogen, USA), following the manufacturer's instructions. The purified rP0 was analysed by sodium dodecyl-polyacrylamide gel electrophoresis (SDS-PAGE) and Western blotting with monoclonal anti-histidine antibody (GE, UK).

Protein concentration was determined by SDSPAGE stained with Coomassie blue by comparison with known concentrations of bovine serum albumin using the LabImage v.3.3.2 image analysis software (Loccus, Brazil).

Serum samples - Cattle serum samples negative for antibodies to B. bovis and B. bigemina were collected from tick-free areas of RS $(n=33)$ and Paraíba $(n=29)$, Brazil and from cattle kept in a tick-free isolation area of Embrapa Beef Cattle, Campo Grande, MS, Brazil ( $\mathrm{n}=$ 67). Serum samples from cattle naturally infected with B. bovis were obtained from state of Pará (PA), Brazil (n $=133$ ). These serum samples were analysed by a crude B. bovis antigen ELISA (Madruga et al. 2000). Serum samples from cattle experimentally infected with $B$. bovis $(\mathrm{n}=77)$ or $B$. bigemina $(\mathrm{n}=36)$ were obtained from the South Embrapa Cattle and Sheep Research Centre, Bagé, RS, Brazil. These animals were raised in a tickfree area and were periodically tested for antibodies to $B$. bovis, B. bigemina and Anaplasma marginale by the immunofluorescent antibody test and examination of stained blood smears. Experimental infections with $B$. bovis or $B$. bigemina were carried out by the subcutaneous route with pure isolates kept in liquid nitrogen and sera were collected 30 days post-inoculation.

Standardisation of ELISA with rPO - Optimal dilutions of antigen, sera and conjugate were determined using six sera negative and six sera positive for antibodies against $B$. bovis. Then, 96-well Costar 3590 plates (Corning, USA) were adsorbed with $1 \mathrm{ng} / \mathrm{mL}$ of rP0 (100 $\mu \mathrm{L} /$ well) diluted in phosphate buffer containing $0.1 \%$ Tween 20 (PBST) for $12 \mathrm{~h}$ at $4^{\circ} \mathrm{C}$. Plates were blocked with PBST with $5 \%$ skim milk for $1 \mathrm{~h}$ at $37^{\circ} \mathrm{C}$. After five washes with PBST, control and test sera (in duplicate) - diluted 1:800 in PBST - were incubated for $60 \mathrm{~min}$ at $37^{\circ} \mathrm{C}$. Plates were then washed five times with PBST and $100 \mu \mathrm{L} /$ well of rabbit anti-bovine IgG horseradish peroxidase conjugate (Sigma A5295, USA) diluted 1:10,000 in PBST was added. Plates were incubated for $30 \mathrm{~min}$ at $37^{\circ} \mathrm{C}$ and, after five washes with $\mathrm{PBST}$, reactions were revealed with Fast-OPD $(50 \mu \mathrm{L} /$ well; Sigma, USA). The reaction was stopped by the addition of $100 \mu \mathrm{L} /$ well of $\mathrm{H}_{2} \mathrm{SO}_{4}(2.5 \mathrm{~N})$ and results were read on an EL-800 ELI$\mathrm{SA}$ reader (Bio-Tek, USA) with a 490-nm filter.

$\operatorname{Ig} G_{1}$ and $\operatorname{IgG}$ titration - For titration of anti-rP0 IgG1 and $\mathrm{IgG} 2$, sera from 30 cattle naturally infected with $B$. bovis from PA were tested as described above, except that sera were diluted from 1:100-1:3,800, antibovine $\mathrm{IgG}_{1}$ and $\mathrm{IgG}_{2}$ monoclonal antibodies (Serotec, USA) were diluted 1:5,000 and rabbit anti-mouse IgG horseradish conjugate (Sigma A-9044, USA) was diluted 1:10,000. Titres were defined as the reciprocal of the highest dilution giving a positive result. 
Cutoff selection - The cutoffs of the ELISA tests were determined based on those described by Frey et al. (1998).

Statistical analysis - The means of the optical densities of sera tested for IgG were analysed by ANOVA followed by Tukey's test, with a 95\% confidence level. Titres of $\mathrm{IgG}_{1}$ and $\mathrm{IgG}_{2}$ were analysed by Wilcoxon signed-rank test, with a $95 \%$ confidence level.

\section{RESULTS AND DISCUSSION}

The P0 gene sequences (939 nucleotides) obtained in the present study were deposited in the Genbank database under the following accession: FJ588004 Midwestern isolate, FJ588005 Northeastern isolate, FJ588006 Northern isolate, FJ588007 Southeastern isolate and FJ588008 Southern isolate of B. bovis.

The multiple alignment of P0 DNA sequences revealed a high degree of identity among the Brazilian isolates of $B$. bovis ( $\geq 99 \%)$. The best hit by BLASTn was the Genbank entry AF498365 (99\% nucleotide identity). The amino acid sequence homology among Brazilian isolates was $100 \%$. This demonstrates that P0 is highly conserved among isolates of $B$. bovis, which is a key prerequisite for any subunit vaccine candidate.

The $\mathrm{P} 0$-deduced amino acid sequences of the Brazilian isolates of $B$. bovis were aligned with $\mathrm{P} 0$-deduced amino acid sequences of $B$. bovis USA AAM18123, Babesia caballi BAF91359, B. bigemina BAF91357, Babesia gibsoni BAF45423, Babesia equi BAF91358, Theileria annulata XP_954430, N. caninum BAF62528, T. gondii AAK69358 and B. taurus AAI51696. A considerable level of homology was observed between the P0 sequences of the Brazilian isolates of $B$. bovis and $B$. caballi (85\%), B. bigemina (84\%), B. gibsoni (80\%), B. equi (67\%), T. annulata (62\%), N. caninum (58\%) and T. gondii (58\%). This high degree of homology may explain the serological cross-reactivity or cross-protective immunity between the $\mathrm{P} 0$ proteins of $B$. gibsoni and $B$. microti (Terkawi et al. 2007b), B. gibsoni and B. rodhaini (Terkawi et al. 2008), B. gibsoni and B. bovis (Terkawi et al. 2007a) and others. The high degree of homology also suggests that P0 may be a universal immunogen against bovine babesiosis caused by B. bovis and B. bigemina. Nevertheless, there was considerable homology between the P0 proteins from B. bovis and B. taurus $(46 \%)$. This indicates the possibility that immunisation with $\mathrm{rP} 0$ from $B$. bovis may generate autoimmune antibodies in cattle. The phylogenetic analysis resulted in a tree with two branches (Fig. 1). The first one included Apicomplexa parasites, with a subgroup containing all the isolates of $B$. bovis (Brazilian and North American), another subgroup with $B$. bigemina, $B$. caballi and $B$. gibsoni, a third subgroup with $T$. annulata and $B$. equi and the last one with the Sarcocystidae N. caninum and T. gondii. The second branch was of $B$. taurus.

The high degree of $\mathrm{P} 0$ conservation among protozoa and even in mammals, suggests that this protein plays an important role in cell metabolism. P0 has been associated with DNA repair, cell development, apoptosis and carcinogenesis (Brockstedt et al. 1998, Frolov \& Birchler 1998, Liliensiek et al. 1998). Moreover, P0 is a structural component, together with $\mathrm{P} 1$ and $\mathrm{P} 2$, of the $60 \mathrm{~S}$ ribosomal subunit of eukaryotes (Uchiumi et al. 1987) and, in knockout studies on $S$. cerevisiae, $\mathrm{P} 0$ was shown to be vital to cell survival (Santos \& Ballesta 1994).

$\mathrm{rP0}$ from $B$. bovis was produced as a $6 \mathrm{x}$-histidine-tag fusion, resulting in a protein of approximately $37 \mathrm{kDa}$ viewed by SDS-PAGE and western blotting (Fig. 2). This molecular mass is consistent with the fusion protein,

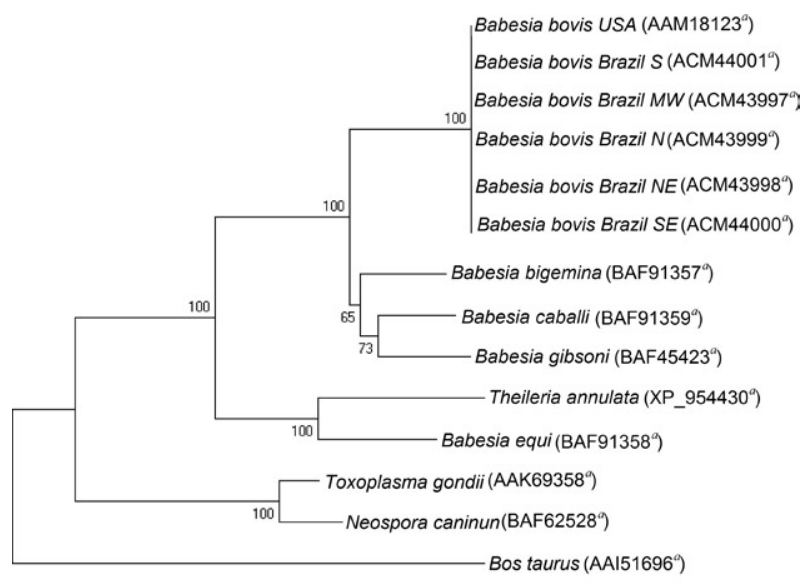

Fig. 1: phylogenetic analysis of deduced amino acid sequences of P0 from Brazilian isolates of Babesia bovis, other species of Babesia, other Apicomplexa and Bos taurus. a: NCBI Genbank accession; MW: Midwest Region; N: North Region; NE: Northeast Region; S: South Region; SE: Southeast Region.
A

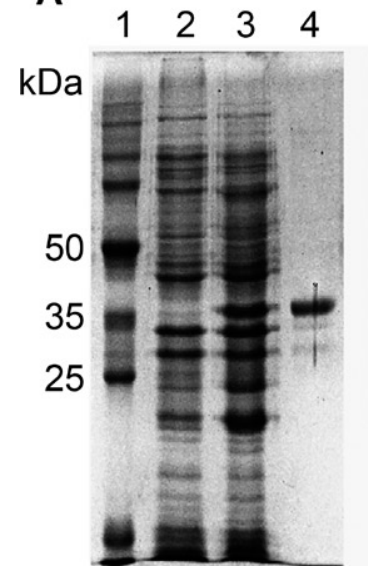

B

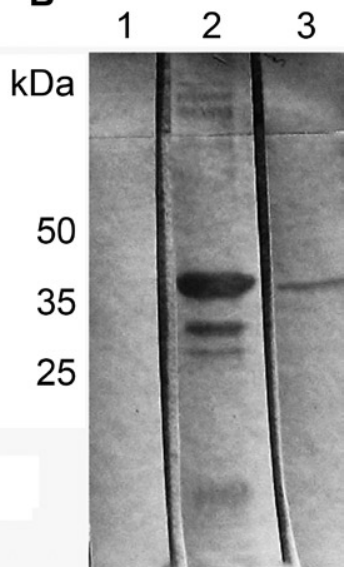

Fig. 2A: Coomassie blue-stained sodium dodecyl-polyacrylamide gel electrophoresis (SDS-PAGE) profile of Escherichia coli BL-21 extracts expressing P0 gene from a Brazilian isolate (Southern Region) of Babesia bovis. Lanes 1: molecular mass marker (Promega ref V8491); 2: extract of E. coli BL-21; 3: BL-21 cells transformed with $p R 7 / \mathrm{P} 0$; 4: semi-purified recombinant $\mathrm{P} 0$; $\mathrm{B}$ : Western blot analysis with recombinant $\mathrm{P} 0$ (rPO) from a Brazilian isolate (Southern Region) of Babesia bovis and anti-6x histidine monoclonal antibody (GE, UK). Lanes 1: extract of E. coli BL-21; 2: BL-21 cells transformed with $p R S E T c / P 0 ; 3$ : purified $\mathrm{rPO}$. 
including the his-tag ( $\sim 3 \mathrm{kDa})$ and P0 (34 kDa). Using anti-sera against $B$. gibsoni $\mathrm{P} 0$, Terkawi et al. (2007a) detected protein bands of 31-34 $\mathrm{kDa}$ in lysates of $B$. gibso$n i, B$. bovis, B. bigemina, B. equi and B. caballi through western blot analysis.

The recognition of $\mathrm{rP} 0$ from $B$. bovis by cattle $\mathrm{IgG}$ was evaluated by ELISA (Fig. 3). Among the 77 sera from cattle experimentally infected with B. bovis, 75 $(97.4 \%)$ were positive in the rP0 ELISA. Out of 133 sera from cattle naturally infected with B. bovis, 127 (95.5\%) were positive. Out of 129 sera from cattle negative for $B$. bovis by ELISA with crude $B$. bovis antigen, 128 (99.2\%) were also negative in the rP0 ELISA.

To investigate whether $\mathrm{rP} 0$ from $B$. bovis is recognised by $B$. bigemina antibodies, sera from cattle exclusively infected with $B$. bigemina were tested with $\mathrm{rP} 0$ by ELISA (Fig. 3). Out of 36 sera analysed, 34 (94.4\%) were positive in the rP0 ELISA. Serological cross-reactions against $\mathrm{P} 0$ have been described among Babesia species (Terkawi et al. 2007a) and between Plasmodium falciparum and T. gondii (Sehgal et al. 2003). The cross-reaction found in the present paper suggests that $\mathrm{P} 0$ proteins from $B$. bovis and B. bigemina share immunodominant epitopes and raises the possibility that such epitopes may be involved in a cross-protective immune response.

rP0 from $B$. bovis was also recognised by $\mathrm{IgG}_{1}$ and $\mathrm{IgG}_{2}$ antibodies from 30 cattle naturally infected with $B$. bovis from PA, with a significantly higher titre of $\operatorname{IgG}_{2}$ (p $=0.0121$ ) (Fig. 4). Th1 responses, including the production of interferon- $\gamma$, activation of macrophages and production of the $\operatorname{IgG}_{2}$ isotype by $\mathrm{B}$ cells, have been associated with immunity against intra-erythrocytic pathogens (Brown et al. 1998, Aguilar-Delfin et al. 2003).

There is the possibility that the $\operatorname{IgG}, \operatorname{IgG}_{1}$ and $\operatorname{IgG}_{2}$ responses found in the present study may be elicited by cross-reactions with antibodies against $\mathrm{P} 0$ proteins from other Apicomplexa parasites, such as $N$. caninum. Nevertheless, only $0.8 \%$ of the sera collected from cattle raised in

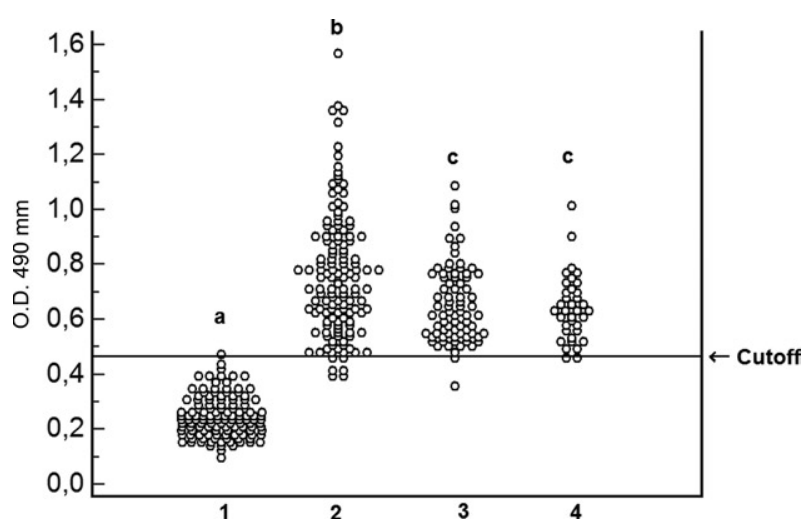

Fig. 3: distribution of optical densities of cattle sera in ELISA test with Babesia bovis recombinant P0. 1: cattle negative for Babesia bovis; 2 : cattle naturally infected with $B$. bovis; 3 : cattle experimentally infected with $B$. bovis; 4 : cattle experimentally infected with Babesia bigemina. Different letters indicate significant statistical differences by ANOVA and Tukey's test (95\% confidence level).

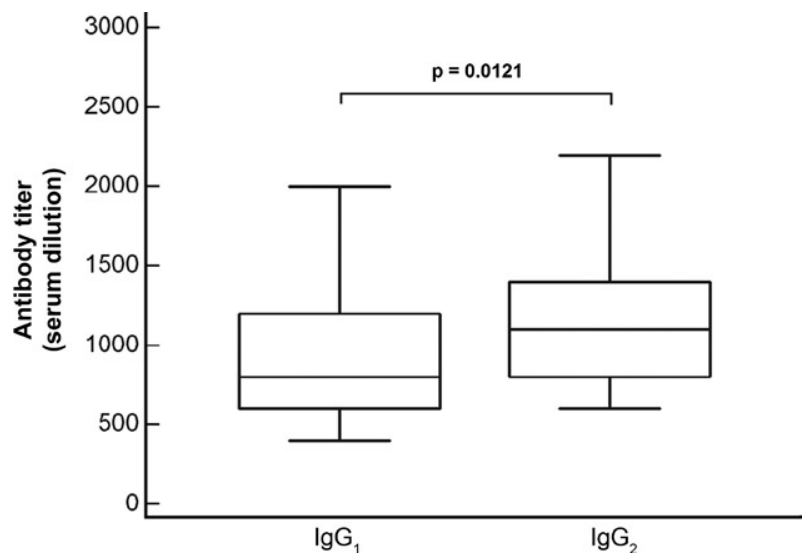

Fig. 4: $\operatorname{IgG}_{1}$ and $\operatorname{IgG}_{2}$ titers anti- recombinant $\mathrm{P} 0$ of Babesia bovis in 30 cattle naturally infected from the state of Pará, Brazil. Titers of $\mathrm{IgG}_{1}$ and $\mathrm{IgG}_{2}$ were analyzed by Wilcoxon signed-rank test, with a $95 \%$ confidence level.

tick-free areas did not react with $\mathrm{rP} 0$, suggesting that crossreactions are relevant only at the Babesia genus level.

In summary, the results of the present paper indicate the high conservation of $B$. bovis P0 not only between different $B$. bovis Brazilian isolates, but also between many protozoan parasites, as well as the antigenicity of rP0 with $B$. bovis and B. bigemina-infected sera. These two characteristics are desirable for the subunit vaccine.

\section{REFERENCES}

Aguilar-Delfin I, Wettstein PJ, Persing DH 2003. Resistance to acute babesiosis is associated with Interleukin-12 and gamma interferon mediated responses and requires macrophages and natural killer cells. Infec Immun 71: 2002-2008.

Bock R, Jacckson L, de Vos A, Jorgensen W 2004. Babesiosis of cattle. Parasitology 129: 247-269.

Bono MF, Mangold AJ, Baravalle ME, Valentini BS, Thompson CS, Wilkonsky SE, Echaide IE, Farber MD, Torioni De Echaide SM 2008. Efficiency of a recombinant MAS-2c-based ELISA to establish the persistence of antibodies in cattle vaccinated with Babesia bovis. Vet Parasitol 157: 203-210.

Brayton KA, Lau AO, Herndon DR, Hannick L, Kappmeyer LS, Berens SJ, Bidwell SL, Brown WC, Crabtree J, Fadrosh D, Feldblum T, Forberger HA, Haas BJ, Howell JM, Khouri H, Koo H, Mann DJ, Norimine J, Paulsen IT, Radune D, Ren Q, Smith RKJr, Suarez CE, White O, Wortman JR, Knowles DP Jr, McElwain TF, Nene VM 2007. Genome sequence of Babesia bovis and comparative analysis of apicomplexan hemoprotozoa. PLoS Pathog 3: 1401-1413.

Brockstedt E, Rickers A, Kostka S, Laubersheimer A, Dorken B, Wittmann-Liebold B, Bommert K, Otto A 1998. Identification of apoptosis-associated proteins in a human Burkitt lymphoma cell line Cleavage of heterogeneous nuclear ribonucleoprotein A1 by caspase 3. J Biol Chem 273: 28057-28064.

Brown WC, Norimine J, Goff WL, Suarez CE, Mcelwain TF 2006. Prospects for recombinant vaccines against Babesia bovis and related parasites. Parasite Immunol 28: 315-327.

Brown WC, Shkap V, Zhu D, McGuire TC, Tuo W, McElwain TF, Palmer GH 1998. CD4+ T-lymphocyte and immunoglobulin G2 responses in calves immunized with Anaplasma marginale outer 
membranes and protected against homologous challenge. Infect Immun 66: 5406-5413.

Chatterjee S, Singh S, Sohoni R, Kattige V, Deshpande C, Chiplunkar S, Kumar N, Sharma S 2000. Characterization of domains of the phosphoriboprotein P0 of Plasmodium falciparum. Mol Biochem Parasitol 107: 143-154.

Clark IA, Jacobsen L 1998. Do babesiosis and malaria share a common disease process? Ann Trop Med Parasitol 92: 483-488.

de Vos A, Bock RE 2000. Vaccination against bovine babesiosis. Ann NY Acad Sci 916: 540-545.

Felsenstein J 1985. Confidence limits on phylogenies: an approach using the bootstrap. Evolution 39: 783-791.

Frey A, Di Canzio J, Zurakowski D 1998. A statistically defined endpoint titer determination method for immunoassays. $J$ Immunol Methods 221: 35-41.

Frolov MV, Birchler JA 1998. Mutation in P0, a dual function ribosomal protein/apurinic/apyrimidinic endonuclease, modifies gene expression and position effect variegation in Drosophila. Genetics 150: 1487-1495.

Gaffar FR, Yatsuda AP, Franssen FF, Vries EA 2004. Babesia bovis merozoite protein with a domain architecture highly similar to the thrombospondin-related anonymous protein (TRAP) present in Plasmodium sporozoites. Mol Biochem Parasitol 136: 25-34.

Iborra S, Carrión J, Anderson C, Alonso C, Sacks D, Soto M 2005. Vaccination with the Leishmania infantum acidic ribosomal $\mathrm{P} 0$ protein plus $\mathrm{CpG}$ oligodeoxynucleotides induces protection against cutaneous leishmaniasis in C57BL/6 mice but does not prevent progressive disease in BALB/C mice. Infect Immun 73: 5842-5852.

Liliensiek B, Rocha M, Umansky V, Benner A, Lin J, Ziegler R, Nawroth PP, Schirrmacher V 1998. Identification of four genes in endothelial cells whose expression is affected by tumor cells and host immune status a study in ex vivo-isolated endothelial cells. Blood 92: 3394-3404.

Madruga CR, Araújo FR, Marques APC, Carvalho CME, Cusinato FQ, Crocci AJ, Kessler RH, Miguita M 2000. Desenvolvimento de uma prova de imunoadsorção enzimática para detecção de anticorpos contra Babesia bovis. Pesq Vet Bras 20: 167-170.

Murrel A, Barker SC 2003. Synonymy of Boophilus Curtice, 1891 with Rhipicephalus Koch, 1844 (Acari: Ixodidae). Syst Parasitol 56: 169-172.

Rajeshwari K, Patel K, Nambeesan S, Mehta M, Sehgal A, Chakraborty $\mathrm{T}$, Sharma S 2004. The P domain of the P0 protein of Plasmodium falciparum protects against challenge with malaria parasites. Infect Immun 72: 5515-5521.
Rich BE, Steitz JA 1987. Human acidic ribosomal phosphoproteins P0, P1 and P2: analysis of cDNA clones, in vitro synthesis and assembly. Mol Cell Biol 7: 4065-4074.

Saitou N, Nei M 1987. The neighbor-joining method: a new method for reconstructing phylogenetic trees. Mol Biol Evol 4: 406-425.

Santos C, Ballesta JPG 1994. Ribosomal protein P0 contrary to phosphoproteins P1 and P2 is required activity and Saccharomyces cerevisiae viability. J Biol Chem 269: 15689-15696.

Sehgal A, Kumar N, Carruthers V, Sharma S 2003. Translocation of ribosomal protein $\mathrm{P} 0$ on Toxoplasma gondii tachyzoite surface. Int J Parasitol 33: 1589-1594.

Singh S, Sehgal A, Waghmare S, Chakraborty T, Goswami A, Sharma S 2002. Surface expression of the conserved ribosomal protein P0 on parasite and other cells. Mol Biochem Parasitol 119: $121-124$

Tamura K, Dudley J, Nei M, Kumar S 2007. MEGA4: Molecular Evolutionary Genetics Analysis (MEGA) software version 4.0. Mol Biol Evol 24: 1596-1599.

Terkawi MA, Jia H, Gabriel A, Goo YK, Nishicawa Y, Yokoyama N, Igarashi I, Fujisaki K, Xuan X 2007a. A shared antigen among Babesia species: ribosomal phosphoprotein $\mathrm{P} 0$ as a universal babesia vaccine candidate. Parasitol Res 102: 35-40.

Terkawi MA, Jia H, Zhou J, Lee E, Igarashi I, Fujisaki K, Nishikawa Y, Xuan X 2007b. Babesia gibsoni ribosomal phosphoprotein P0 induces cross-protective immunity against $B$. microti infection in mice. Vaccine 25: 2027-2035.

Terkawi MA, Zhang G, Jia H, Aboge G, Goo YK, Nishikawa Y, Yokoyama N, Igarashi I, Kawazu SI, Fujisaki K, Xuan X 2008. $\mathrm{C} 3$ contributes to the cross-protective immunity induced by Babesia gibsoni phosphoriboprotein P0 against a lethal $B$. rodhaini infection. Parasite Immunol 30: 365-370.

Uchiumi T, Wahha AJ, Traut RR 1987. Topography and stoichi-ometry of acidic proteins in large ribosomal subunits from Artemia salina as determined by cross linking. Proc Natl Acad Sci USA 84: 5580-5584.

Wright IG, Goodger BV 1988. Pathogenesis of babesiosis. In M Ristic, Babesiosis of domestic animals and man, CRC Press, Boca Raton, 99-118.

Zhang H, Lee E, Liao M, Compaore MKA, Zhang G, Kawase O, Fujisaki K, Sugimoto C, Nishikawa Y, Xuan X 2007. Identification of ribosomal phosphoprotein $\mathrm{P} 0$ of Neospora caninum as a potential common vaccine candidate for the control of both neosporosis and toxoplasmosis. Mol Biochem Parasitol 153: 141-148. 